\title{
Triunfo del nombre de Jesús. Mensaje iconográfico del ábside, cúpula y bóveda de Il Gesú de Roma
}

\author{
Triumph of the name of Jesus. Iconographic message of the apse, dome and vault \\ of Il Gesú of Rome \\ Adrián de Jesús García Mayenco \\ ${ }^{1}$ Departamento Historia del Arte, Universidad de Málaga, España (adri1692@ hotmail.com)
}

Recibido el 01 de enero de 2017; revisado el 05 de febrero de 2017; aceptado el 20 de febrero de 2017; publicado el 01 de marzo de 2017

RESUMEN: Este artículo tiene como fin realizar un primer avance en el estudio del mensaje iconográfico del ciclo pictórico plasmado en las pinturas que decoran el ábside, la cúpula y la bóveda de la iglesia de Il Gesù en Roma (1568-1584), iglesia madre de la Compañía de Jesús fundada por Ignacio de Loyola en 1540. Tras la realización de un estudio del contexto socio-histórico, se puede verificar el establecimiento de un repertorio iconográfico de carácter dogmático y proselitista en pro del catolicismo, que surge con la Reforma Católica y es impulsado por el espíritu combativo y profundamente militante de los jesuitas.

PALABRAS CLAVES: Iconografía, Pintura, Roma, Jesuitas, Barroco.

RIASSUNTO: Questo articolo ha il fine di realizzare un primo avanzo nello studio del messaggio iconografico del ciclo pittorico rappresentato nelle pitture che decorano l'abside, la cupola e la volta della chiesa de Il Gesù a Roma (1568-1584), chiesa madre della Compagnia del Gesù fondata da Ignazio Loyola nel 1540. Precedentemente si è dovuto realizzare uno studio sociale-storico, quello che ci da la possibilità di verificare un insediamento di un nuovo repertorio iconografico di carattere dogmatico proselitista in favore del cattolicesimo, che sorge con la riforma cattolica ed è spinto dallo spirito combattivo e profondamente militante dei gesuiti.

PAROLE CHIAVE: Iconografia, Pittura, Roma, Gesuiti, Barocco.

"En este día, el nombre de Cristo ha sido asociado a su sangre; por este motivo, nosotros los jesuitas debemos estar dispuestos a dar nuestra sangre por este nombre” Imago primi saeculi. 
Casi en el mismo momento en el que tiene lugar el Concilio de Trento, es fundada la Compañía de Jesús por Ignacio de Loyola, la cual tuvo un papel relevante para promover e impulsar los mecanismos de la Reforma Católica. En este contexto, se puede destacar la ciudad de Roma como lugar de gran actividad constructiva, muestra de ello es la iglesia del Gesù, sede congregacional jesuita, cuya tipología será modelo para las iglesias posteriores.

A pesar de la importancia que conllevó la construcción de la iglesia del Gesù y los numerosos estudios que se han realizado sobre ella, en especial acerca de su estilo y fachada, son escasas las investigaciones que se han llevado a cabo del programa iconográfico que lo decora, haciendo que la visión de conjunto sea incompleta. Se ha señalado asiduamente que se trata de un modelo de iglesia que estaría vigente hasta finales del siglo XVII y principios del XVIII, pero en muy pocas ocasiones se ha hecho referencia a su condición de soporte material y físico de uno de los programas iconográficos más importantes del Barroco.

Por tanto, en cuanto al ámbito pictórico, es necesario señalar que tendrá un papel muy importante, ya que fue el momento en el que la pintura barroca en Roma se caracteriza por la realización de obras maestras que sirvieron de punto de referencia en el arte de la mayor parte del siglo, siendo un ejemplo de ello la magna obra que realizó Gaulli1 para la bóveda. Teniendo en cuenta los problemas iconográficos que surgieron, se rechaza parte del repertorio medieval y se crean otros en el que prima el carácter antiprotestante.

\section{Mensaje iconográfico: el espacio como soporte de un programa}

Antes de entrar en la descripción de la iconografía que decora el ábside, la cúpula y la bóveda de la iglesia del Gesù, se plantearán resumidamente los nuevos aspectos iconográficos adoptados por los jesuitas tras el Concilio de Trento. Fue con la Reforma Católica cuando se implantó un nuevo arte donde prima un repertorio iconográfico con carácter de oposición contra la herejía protestante, creando así una nueva iconografía cristiana de carácter dogmático. Por tanto, este renovado arte católico, animado por el espíritu combativo de la Compañía de Jesús, convierte el repertorio de temas, siguiendo las palabras de Réau (2000, p.90) "en un arsenal de municiones contra la herejía antipapista".

El arte barroco no se limita sólo a renovar el repertorio de temas con respecto a la Edad Media -se eliminaron algunos temas tradicionales para imponerse aquellos de propaganda antiprotestante-, sino que también se introducen temas poco conocidos como son la representación del triunfo y del éxtasis (Réau, 2000, p. 548). En definitiva, es evidente afirmar que el siglo XVI cuenta con su propia iconografía, conformada por la mezcla entre la tradición del pasado y el espíritu de los tiempos, y que fue desarrollada en Roma por los Carracci2, para luego extenderse por toda Europa.

\footnotetext{
${ }^{1}$ Giovanni Battista Gauli "Il Baciccio" es un pintor italiano que, durante su aprendizaje, estudió a grandes maestros, hasta convertirse en uno de los artistas más ilustres de toda Italia al especializarse en el retrato y, sobre todo, tras encargarse de la decoración pictórica de numerosas iglesias de Roma, pudiendo destacar el fresco situado en la bóveda de la iglesia del Gesú como su opera prima.

${ }^{2}$ Los Carracci -Ludovico, Annibale y Agostino- son una familia de artistas italianos que fundaron la Accademia dei Desiderosi, posteriormente deminada Accademia degli Incamminati, basada fundamentalmente en el dibujo y el estudio de anatomía, inspirada en la naturaleza, buscando nuevas posibilidades de representación artística.
} 


\subsection{Iconografía jesuítica}

La mayor parte de los temas introducidos en este arte renovado promovido por la Reforma Católica, fueron tomados por los jesuitas. Según los que se encuentran en la iglesia del Gesù, podremos dividirlos en dos grupos: los que tienen carácter combativo contra la herejía luterana y calvinista, iconografía plasmada en las capillas laterales de la iglesia; y los que son propiamente jesuitas, es decir, los que aluden a hechos acaecidos en relación a la figura de Jesús y serán los más importantes para la Compañía.

A este primer grupo pertenece el tema de la devoción a los arcángeles, que, según Mâle (1985, p. 262), fue uno de los temas que Roma aportó al mundo en el siglo XVI, alcanzando su mayor grado de apogeo en el siglo XVII, pues es cuando se le dedican capillas, como es el caso del Gesù.

Otro de los temas que se consideran refutación del protestantismo es la devoción a los santos, que para los jesuitas es importante, pues con ello se quería exaltar el hecho de que derramaron su sangre para extender el Nombre de Jesús en el mundo (Sebastián, 1981, p. 276). Otros temas pertenecientes a este grupo es la veneración de la Virgen, como protesta a la crítica al respecto que configuran los luteranos, y la representación del tema de las almas redimidas del Purgatorio (Mâle, 1985, p. 371).

Este segundo grupo lo configuran dos temas; uno de ellos es el de la Circuncisión, de gran importancia para los jesuitas ya que es cuando el Niño recibe el Nombre de Jesús, siendo por ello uno de los asuntos más representados en la iglesia de los jesuitas como la de Sant'Ambrogio en Génova y en la del Gesù, propiamente dicha, que se encuentra en el ábside.

El otro es la Adoración de la Trinidad, que se trata de un tema primario en el pensamiento jesuítico, por cuanto que es de recordar que San Ignacio había dado el nombre de Jesús a su Compañía después de la milagrosa aparición de Cristo con la cruz a cuestas y las otras dos personas de la Santísima Trinidad a las puertas de Roma en la denominada Visión de la Storta3 (Mâle, 1985, p. 370).

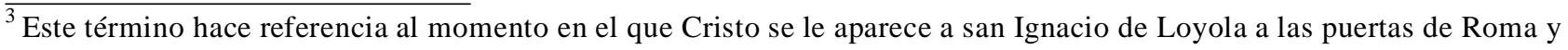
le pronuncia estas palabras: "Ego vobis Romae propitius ero" (Yo os seré favorable en Roma).
} 


\section{El cosmos jesuita. El triunfo del nombre de Jesús}

Capilla Mayor:

(1) La Circuncisión

(2) La Adoración del

Cordero Místico

(3) Coro de ángeles

Pechinas:

(4) Los Padres de la Iglesia

(5) Los Evangelistas

(6) Profetas

(7) Profetas

Cúpula:

(8) Gloria en el Paraíso

\section{Bóveda:}

(9) Triunfo del Nombre de Jesús.

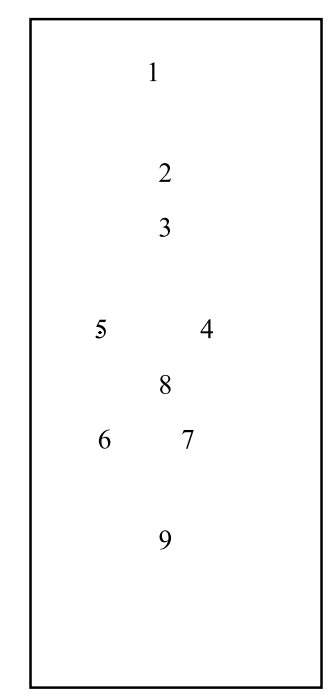

\section{1. Ábside}

En el altar mayor se dispone uno de los temas más importantes para la Compañía jesuita: $L a$ Circuncisión. Es una obra realizada por Alessandro Capalti en 1842, sustituyendo a la obra de Girolamo Munziano. Se trata del momento en el que el Niño recibió el nombre de Jesús, el cual posteriormente fue adoptado por san Ignacio de Loyola. La importancia de este tema se debe a que esta asociación del Nombre de Jesús con su sangre en la Circuncisión fue el hecho central de la predicación jesuita, tal y como se señala en el libro Imago primi saeculi, realizado por el centenario de la orden: "En este día, el nombre de Cristo ha sido asociado a su sangre; por ese motivo, nosotros los jesuitas, debemos estar dispuestos a dar nuestra sangre por este nombre".

Esta costumbre era muy importante para los judíos, a pesar de que fue tomada de los egipcios, pues se convirtió en el signo de alianza entre el pueblo de Israel con Yavéh. Además, la circuncisión era y sigue siendo para los judíos lo que el bautismo ha sido para los cristianos, pues es cuando reciben el nombre.

Iconográficamente, esta obra se basa en las representaciones que se hicieron a partir de la Reforma Católica, pues en el centro se dispone el sacerdote o mohel, sosteniendo al Niño en movimiento entre sus brazos. Junto a él, se encuentra la figura de María, siendo consolada por su esposo José, además de dos personajes secundarios, como son un hombre y una mujer que observan lo acaecido. 
Este nuevo esquema incluye la representación de los ángeles, en este caso aparecen seis, los cuales sostienen los atributos de la pasión (corona de espinas, cáliz y la lanza con la esponja), y se encuentran separados en dos grupos de tres por una cruz, de la que cuelga una pequeña tabla con el nombre de JESUS. Con esta representación, la Circuncisión queda relacionada con la Pasión, afirmándose la idea de que el Hijo de Dios vierte por primera vez la misma sangre que posteriormente correría en la Flagelación y en la Cruz para redimir los pecados del hombre (Réau, 1996b, p. 268).

La importancia de este tema quedará patente en la iglesia madre de los jesuitas pues, de nuevo, se hace alusión a este tema en la capilla de la Sagrada Familia, así como en otras iglesias como la de los jesuitas de Amberes o la de Sant'Ambrogio, en Génova, donde Rubens lo representa también sobre el altar principal.

En cuanto a la bóveda del ábside y en el arco del presbiterio, se encuentran dos de las obras que realizó Giovanni Battista Gaulli entre 1680 y 1685 para esta iglesia jesuita. En la bóveda representó La adoración del Cordero Místico, según se lee en el Apocalipsis (Ap. 5, 6-7): "Entonces vi, de pie, en medio del trono y de los cuatro Vivientes y de los Ancianos, un Cordero como degollado; tenía siete cuernos y siete ojos, que son los siete espíritus de Dios, enviados a toda la tierra. Y se acercó a y tomó el libro de la mano derecha del que está sentado en el trono".

En este sentido, es de destacar que a pesar de las numerosas referencias que se muestran en el Antiguo y Nuevo Testamento sobre la identificación de Cristo con el cordero, en este caso, Gaulli se basa en el Apocalipsis (Carvajal, 2010). Tal y como vemos por la descripción, a modo de rompimiento de gloria, se ha representado al cordero místico sobre el Libro de los Siete Sellos, estableciéndose como único juez digno de abrirlo. En torno a éste, una multitud de ángeles se disponen alrededor del trono junto a los Cuatro Vivientes y los veinticuatro Ancianos, quienes se postran ante él ofreciéndoles copas de oro llenas de perfumes que son las oraciones de los santos. Por tanto, con esta representación se alude al carácter sacrificial y simboliza el triunfo del Salvador sobre la muerte encarnando, a la vez, los dos aspectos del Cristo sufriente y triunfante (Réau, 2000, p. 99).

En el arco del presbiterio se dispone el fresco que Gaulli realizó a la par que la bóveda del ábside, en el que representó un Concierto de ángeles. Sobre un cielo de nubes, se pueden observar ángeles mancebos tocando diferentes instrumentos (violín, viola, pandero, arpa), mientras que otros tres sostienen una filacteria con la inscripción Vocatum est nomen eius Iesus. A este concierto de ensalzamiento y glorificación del nombre de Jesús asisten numerosos puttis, cuyas cabezas aparecen entre las nubes.

\subsection{Cúpula}

En el centro del crucero se alza la cúpula realizada por Giacomo Vignola y decorada por Giovanni Battista Gaulli entre 1672 y 1675, en la que representó la Gloria del Paraíso. Ésta es sostenida por pechinas, también decoradas por Gaulli, en las que aparecen los Padres de la Iglesia - San Gregorio Magno, San Jerónimo, San Agustín y San Ambrosio-. 
En otra de las pechinas se encuentran Los Evangelistas -San Mateo, San Marcos, San Lucas y San Juan- destacando la figura de San Lucas como pintor de la Virgen, ya que aparece con un retrato de ella, inspirado en el de Salus Populi Romani situado en la basílica de Santa María Maggiore.

Por último, en las dos pechinas restantes se encuentran los Profetas. En la de la izquierda, se representan a David, Moisés, Zacarías y Jonás. Esto es muy interesante en la medida en la que los cuatro Profetas aluden a la figura de Cristo, pues David se asocia con él en que fue Rey; a Moisés también se le relaciona por ser el libertador; a su vez, la figura de Zacarías hace mención a Cristo por ser el que anunció su entrada en Jerusalén montado en un asno y la traición de Judas por treinta monedas de plata (Réau, 1996a, p. 300), mientras que el episodio de Jonás en el vientre de la ballena, es considerado una prefiguración de la Resurrección de Cristo, pues, al igual que Jonás, que permaneció tres días en el vientre de la ballena y salió vivo, Cristo resucitó después de tres días (Réau, 1996a, p. 300).

Finalmente, en la pechina restante aparecen otros cuatro profetas que no están identificados claramente pero que, por los atributos, podríamos señalar que se tratan de Daniel con la presencia del león, e Isaías con la sierra. Los dos restantes no presentan atributos identificativos, pero podrían tratarse de Habacuc y Ezequiel, ya que, conceptualmente, son los más apropiados.

Por tanto, en las pechinas se disponen los escritores escogidos por Dios para anunciar la llegada del Redentor, recoger sus predicaciones y ser testimonios de su fe, a la vez que todos ellos parecen insertos en el interior de las pechinas en grupos de cuatro.

En cuanto a la cúpula propiamente dicha, se trata de una especie de cielo que se eleva sobre la tierra, en el que están representados numerosos ángeles, revoloteando y tocando instrumentos musicales y el Espíritu Santo en forma de paloma, simbolizando la gracia que desciende hasta la tierra y la inunda de vida. También se representa a Dios Padre con Jesucristo situado a la derecha, y la Virgen a la derecha. Bajo la figura del Cristo aparece un ángel que sostiene una cruz a la que se abrazan Adán y Eva, símbolos de la victoria del Salvador sobre el pecado.

A ambos lados de este grupo, vemos cómo las dos piedras angulares del Iglesia muestran a Dios los dos pilares fundamentales de la Compañía de Jesús. En la parte de la cúpula que coincide con el altar de san Ignacio de Loyola, aparece el santo fundador, ataviado con la ropa sacerdotal, siendo presentado por san Pedro y acompañado por san Benito. Mientras que, en el lado del altar de san Francisco Javier, aparece el misionero, ataviado con la estola y la esclavina, siendo entregado a Dios Padre por san Pablo. Entre todos los santos y beatos, podrían aparecer los jesuitas Juan Berchmans, Luis Gonzaga y Estanislao Kotska.

\subsection{Bóveda}

Antes de comentar el majestuoso fresco que hizo Gaulli en la bóveda de la iglesia madre de los jesuitas, hay que hacer una breve referencia acerca del periodo en el que vivía el autor para entender qué es lo que le llevó a hacer dicha obra. En la Roma del Seicento impera el gusto por lo barroco, cuyo lenguaje se instaura gracias a la labor de diversos papas y artistas, siendo uno de ellos Giovanni Battista Gaulli. 
Estos artistas utilizaron algunos efectos como elllamado ilusionismo pictórico, así como la perspectiva y las líneas curvas para dar mayor dinamismo y movimiento, y conseguir engañar al espectador creando la sensación de que forman parte de una ilusión. De ahí la idea de que el Barroco es pura teatralidad. Fue a partir de entonces cuando se hacen este tipo de obras, instaurándolas en el interior de las iglesias, teniendo como finalidad exaltar la grandiosidad de la Iglesia Católica y atraer más fieles.

En el caso de la iglesia del Gesú, fue el padre Gian Paolo Oliva, general de la Compañía de Jesús entre 1661 y 1681, el que eligió a Gaulli para realizar los frescos y el proyecto de los estucos para su posterior realización por Antonio Raggi, siendo el año 1672 cuando recibió el encargo de pintar el Triunfo del Nombre de Jesús en la bóveda de la nave central, y el de 1679 el de su finalización (Anónimo, 2004).

Se trata de una obra cargada de simbolismo tanto para los jesuitas como para la iglesia católica, al ser un ensalzamiento del nombre de Cristo, que expulsa de su gloria a todos aquellos que representen al mal. En el centro aparece el monograma IHS, coronado por una cruz y dispuesto sobre un corazón traspasado por tres clavos, irradiando luz que alumbra a todo el cortejo celestial situado alrededor, formado por putti y ángeles mancebos, a los Santos y a los Reyes que están dispuestos sobre nubes que salen fuera de la techumbre, dotando a la escena de mayor efecto de ilusionismo.

En la obra quedan implícitos los valores simbólicos de la luz de Caravaggio (Tomas et al, 2007, p. 518) y se observa la influencia de Bernini en la composición. En cuanto al monograma del nombre de Jesús, el profesor Sánchez López destaca que se pueden realizar diferentes lecturas de estas siglas.

Una de ellas es la de carácter soteriológico (IESVS HOMINVM SALVATOR) (Sánchez, 1996, p. 94), la cual se encuentra ligada a la cristianización de los epítetos Sol Salutis y Sol Invictus, por cuanto Cristo es Sol de Justicia y, tal y como confirma San Bernardo -segunda interpretación- su Nombre, es alimento, fuente, luz y medicina (IN HOC SALVS) (Sánchez, 1996, p. 94), La tercera interpretación, en nuestro caso es considerada la más importante, hace referencia a la abreviatura del lema de la Compañía de Jesús (HOC VNO EST TANTVM NOMINE CERTA SALVS), utilizando también el acróstico (IESVS HABEMVS SOCIUM) (Sánchez, 1996, p. 94).

Continuando con la descripción de la bóveda, de entre todo el compendio de personajes, en el lado izquierdo se puede destacar la presencia de los Reyes Magos, ofreciéndole al monograma el oro, el incienso y la mirra. Detrás de ellos, aparece el rey san Luis, con el mando constelado de flores de lis, representando a la corona francesa. Sin embargo, en la nube situada a la derecha, algunos de los personajes que podemos identificar son San Pío V, ataviado con la casulla y arrodillado con los brazos abiertos, y San Fernando. Otros personajes que podrían estar representados son Alessandro Farnese, por ser el cardenal que financió la construcción, y Roberto Belarmino pero por la falta de documentación, no podemos verificarlo.

Por tanto, el grupo de personajes que participan de la glorificación del Nombre de Jesús concluye con la representación de unas figuras femeninas, que podrían ser Santas representadas sobre la nube central, en cuya parte inferior aparece un ángel que expulsa de la gloria al conjunto de personajes que se encuentran acumulados en la parte final de la bóveda. Se tratan personificaciones de 
los vicios y los pecados. De ahí que, de entre esa masa de figuras, se puedan distinguir la Lujuria mujer con serpiente-la Soberbia - con el pavo real-; la Envidia -Mujer con rostro demacrado y serpiente-; y la Avaricia - mujer con bolsa de dinero-.

\section{Conclusión}

Como ya es sabido, la iglesia del Gesù es una de las más importantes de Roma, por eso ha sido objeto de estudio por parte de numerosos historiadores del arte, sobre todo, en lo tocante a su estilo y fachada. Sin embargo, hay muy pocas indagaciones acerca del programa iconográfico que lo decora.

Por ello, con este artículo se ha pretendido realizar una breve referencia acerca del mensaje que se quería transmitir al fiel a través de la iconografía de los episodios representados en el ábside, la cúpula y la bóveda de la iglesia madre jesuita para dejar constancia de que se trata de un claro ejemplo de las tendencias iconográficas posteriores al Concilio de Trento, el cual implantaría un nuevo tipo de repertorio iconográfico que, como se ha señalado anteriormente, gozará de carácter de oposición y seña de identidad contra los luteranos y calvinista, haciendo de Roma uno de los centros de producción artística más importantes. Por tanto, una de las conclusiones a destacar es la idea del arte comomedio de propaganda impregnado del espíritu religioso de la época.

No sólo se estableció un repertorio iconográfico basado en el espíritu combativo contra la herejía, sino que también se aportaron temas propios de los jesuitas, como el de la Circuncisión, tal y como se observa en el ábside.

En este sentido, podemos señalar que, además de que la iglesia del Gesù de Roma sirva de modelo para otras iglesias posteriores, también será referente en el ámbito pictórico, puesto que la obra que realiza Gaulli para la bóveda alcanza el mayor grado de teatralidad, al mezclar los estucos con el juegos de iluminación y líneas convergentes, para crear mayor tridimensionalidad y hacer creer al observador que la bóveda está abierta y puede ver lo que está ocurriendo, en este caso, la glorificación del Nombre de Jesús que abate al mal.

Por tanto, en definitiva, es necesario exaltar que la iglesia del Gesù acoge unos de los programas iconográficos más interesantes de Roma, donde la calidad artística alcanza su cota más alta y que, junto a la construcción de la iglesia en sí, forman un conjunto donde la perfección y lo sublime están presente.

\section{Referencias bibliográficas}

ANÓNIMO (2004), Studi sul Barocco romano, Skira editore, Milano.

BUSSAGLI, Marco (Ed.) (2007), Roma: La edad de oro, H. T. Ullmann, Barcelona.

CARVAJAL GONZALEZ, Helena (2010), "El Agnus Dei”, en Revista digital de Historia Medieval, vol. II, Nº 4 , pp. 1-7. 
MÂLE, Emile (1985), El barroco. El arte religioso del siglo XVII: Italia, Francia, España, Flandes, Ed. Encuentro, Madrid.

REAU, Louis (1996a), Iconografía del arte cristiano. Iconografía de la Biblia Antiguo Testamento, T. I, vol. 1, Ediciones del Serbal, Barcelona.

REAU, Louis (1996b), Iconografía del arte cristiano. Iconografía de la Biblia Nuevo Testamento, T.I, vol. 2, Ediciones del Serbal, Barcelona.

REAU, Louis (2000), Iconografía del arte cristiano. Introducción general, Ediciones del Serbal, Barcelona.

SÁNCHEZ LÓPEZ, Juan Antonio (1996), El alma de la madera. Cinco siglos de Iconografía y Escultura procesional en Málaga, Hermandad de la Amargura, Málaga.

SEBASTIÁN, Santiago (1981), Contrarreforma y Barroco: Lecturas iconográficas e iconológicas, Alianzas Editorial, D.L, Madrid. 